\title{
Telescopic removal of bullet in a challenging case of gunshot injury
}

\author{
Nilam U. Sathe ${ }^{* 1}$, Sheetal Shelke ${ }^{1}$, Ratnapriya ${ }^{1}$, and Shampa Mishra ${ }^{1}$ \\ ${ }^{1}$ Department of ENT and Head - Neck Surgery, Seth G. S. Medical College and KEM Hospital, Parel, Mumbai, India
}

\begin{abstract}
Introduction: The incidence of gunshot but is wounds on the face has been on a rise still rare as compared to firearm injuries to other regions of the body. Such injuries can be devastating due to the presence of vital structures in the vicinity. We describe a rare case of retained bullet in the infratemporal fossa which presented with delayed onset facial nerve palsy and was meticulously removed with the help of 0 degree endoscope.

Case report: A 36 year old male reported to the emergency department for management of a homicidal gunshot injury to left side of face. The patient developed left sided facial nerve palsy6 days following the episode. Computerised tomography of the face revealed presence of metallic foreign body impacted in the infratemporal fossa with associated mandibular condyle and temporal bone fracture. The bullet was located in a critical position only within $5 \mathrm{~mm}$ of carotid artery. The entry wound was explored and Hopkins O degree endoscope was used to further trace the entry wound down up to the infratemporal fossa.
\end{abstract}

Conclusion: The successful outcome depends on careful planning and multidisciplinary team approach. In our case, we would also like to highlight that the use of endoscope was extremely helpful and helped us to avoid the morbidity associated with external approach.

\section{Introduction}

Firearm wounds in the maxillofacial facial region comprise fourteen percent of all gunshot related assaults. Though the incidence of gunshot wounds to the face have been on a rise but still are rare compared to firearm injuries to other regions of the body [1]. Such injuries can be devastating due to the presence of vital structures in the vicinity. There are controversies regarding the ideal time and treatment of these cases [2]. Here we describe a rare case of retained bullet in the infratemporal fossa which presented with delayed onset facial nerve palsy and was meticulously removed with the help of 0 degree endoscope.

\section{Clinical case}

A 36 year old male reported to the emergency department for management of homicidal gunshot injury to left side of face. The patient had a brief episode of loss of consciousness and was shifted to nearby hospital and for further management patient was referred to our hospital. He initially complained of pain on left side of the face with difficulty in opening mouth and was treated conservatively with wound care and intravenous antibiotics. However, 6 days following the episode the patient developed left sided facial palsy. (Figure 1)

On examination, there was $1 \mathrm{X} 1 \mathrm{~cm}$ entry wound in left pre auricular region, tenderness over the left temporomandibular joint and left sided grade IV Lower Motor Neuron facial nerve palsy. The external auditory canal on the left was filled with blood clots. Computerised tomography of the face revealed presence of metallic foreign body impacted in the infratemporal fossa with mandibular condyle and temporal bone fracture. The bullet was located in a critical position only within $5 \mathrm{~mm}$ of carotid artery.

Though the initial plan of management was conservative, due to development of delayed onset facial palsy patient was taken up for removal of the bullet under general anaesthesia. The patient was taken up for removal of bullet in the ENT Operating Room along with maxillofacial facial surgeon, plastic surgeon and the cardiovascular thoracic team stand by during the case.

Linear preauricular incision was taken posterior to the entry wound, just anterior to the tragus. Entry wound was explored. Branches of the facial nerve were identified and preserved. The root of zygoma and zygomatic arch were exposed and the left temporo-mandibular joint capsule was opened with complete exposure of the condylar head which was found to be fractured and the fracture segments were carefully and completely removed for better access. Hopkins $\mathrm{O}$ degree endoscope was used to further trace the entry wound down up to the infratemporal fossa. The bullet was found embedded in the infratemporal fossa just next to visible pulsations of the carotid artery. The bullet was disimpacted from the surrounding tissues meticulously using a micro-ear ball probe and delivered very carefully using a 0 degree Hopkins rod endoscope. Condylar plating and left eye tarsorhaphy was also done in the same sitting. Post-operative period was uneventful. Post-operative computerised tomography showed complete removal of the bullet. (Figure 2)

\section{Discussion}

Foreign bodies in the head and neck region are often difficult to remove and the approach depends on its size and relationship to

Correspondence to: Dr. Nilam U. Sathe, Associate Professor, Department of ENT and Head - Neck Surgery, Seth G. S. Medical College and KEM Hospital, Parel, Mumbai, India; TeL: +91 9821309298; E-mail: drneelam_s@yahoo.co.in

Key words: Gunshot injury; Telescopic removal

Received: November 20, 2017; Accepted: February 17, 2017; Published: February 22, 2017 


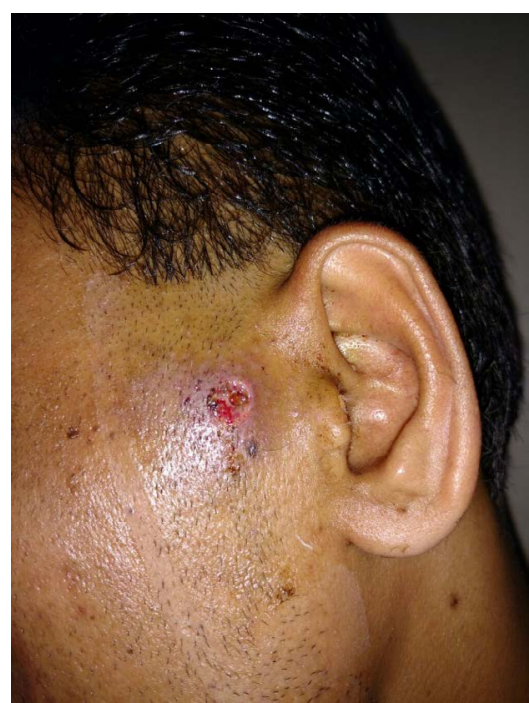

Figure 1. Showing entry wound of Bullet in left preauricular region.

nearby vital structures [3]. Gunshot injuries are often associated with significant morbidity and mortality. Such injuries in the maxillofacial region have unusual and complicated presentation [4]. The anatomical location of the bullet poses a surgical challenge due to its proximity to crucial neurovascular structures.

The factors affecting the extent of gunshot injuries include type of weapon, distance from which patient has been shot, velocity of bullet (low velocity, less than $1000 \mathrm{feet} / \mathrm{sec}$ and high velocity, more than 2000 feet/sec) and tissue resistance. The fundamental classification consists of three classes i.e. penetrating, perforating, and avulsive. Low-velocity projectiles often cause penetrating wounds which have small entrance and exit wounds. On the contrary, high-velocity projectiles mostly cause perforating wounds which pass right through tissues and have small entry wounds and somewhat larger exit wounds [5]. Further, gunshot injuries can be classified into three types depending on the range from which bullet has been shot, where type 1 consists of those penetrating only subcutaneous tissue and fascia (long range, over 7 yards), type 2 includes those penetrating internal cavities (3-7 yards) and blast injuries come under type 3 ( less than 3 yards). Type 2 and 3 injuries may lead to severe tissue damage and fracture of bones. Also, subject to the tract that is formed by the bullet trajectory, the injuries can be divided into four groups: (1) through and through wound (2) tangential damage in the absence of any entry or exit wound (3) bullet retained in body and palpable under skin. (4) Bullet retained in body and not palpable under skin $[2,6,7]$. According to this classification our patient belonged to type 4(bullet residing in the infratemporal fossa).

Gunshot injuries are generally treated conservatively as the surgical procedures may pose a greater risk than that associated with systemic lead intoxication by a retained bullet [8]. In our case, since the patient did not have any significant complaints on presentation, he was managed conservatively with intravenous antibiotics and wound care.

The retained bullets in soft tissue and bone leads to fibrous tissue formation preventing dissolution of lead [9]. However, some cases of arthropathy [10] and systemic lead intoxication in patients have been described where bullets were in contact with synovial and cerebro-spinal fluids [11]. Owing tophysical and chemical properties, metalliclead dissolves in acidic media leading to toxic effects such as the central and peripheral neuropathy, nephropathy and haemolytic anaemia [11]. As retained bullet may lead to poisoning, fistula formation, recurrent infections, or secondary haemorrhage, its removal has been deemed necessary even in the absence of clinical symptoms [12]. Some non-specific symptoms associated with plumbism consist of anorexia, vomiting, constipation, abdominal pain, anaemia, renal toxicity, acute encephalopathy with lethargy, stupor and coma in extreme cases [13]. (Figure 3)

Here, in our case, though the patient did not show any signs of systemic lead intoxication, he developed late onset Lower Motor Neuron grade IV facial palsy 6 days following the assault and this made the removal of the bullet a necessity. Thus we went ahead and took the patient for removal under general anaesthesia with the help of maxillofacial surgeon and plastic surgeon and successfully removed the bullet from the infratemporal fossa using 0 degree Hopkins endoscope. It has been seen that the outcome significantly improves with proper diligent planning and skilled team [14] (Figure 4).

\section{Conclusion}

We would like to conclude that foreign body in the maxillofacial region is a therapeutic challenge for the otorhinolaryngologist. The

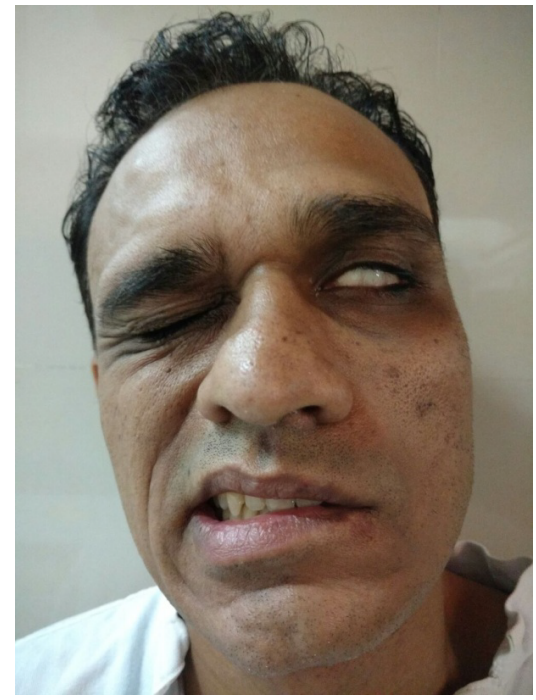

Figure 2. Patient showing left sided lower motor neuron facial nerve palsy.

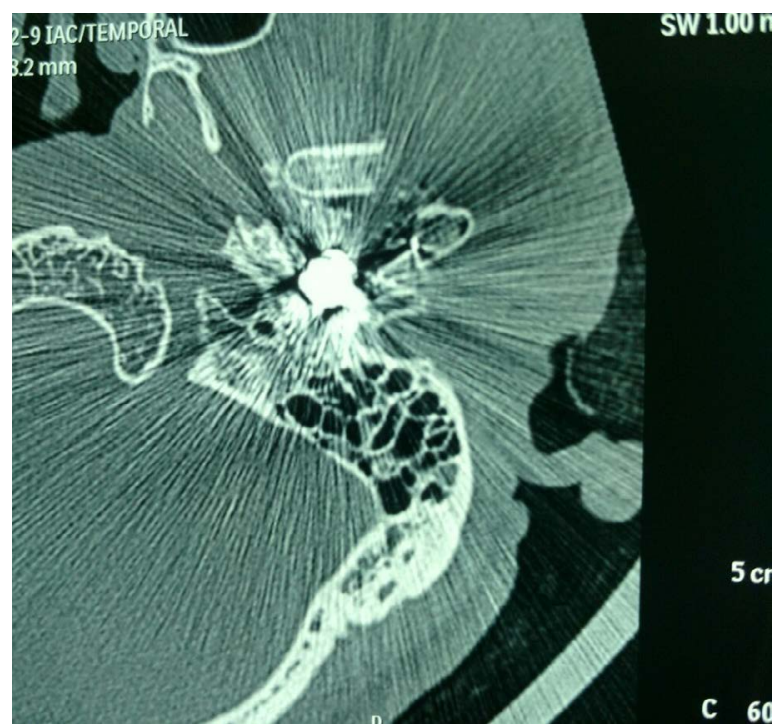

Figure 3. CT scan showing metallic foreign body in left Infratemporal fossa. 


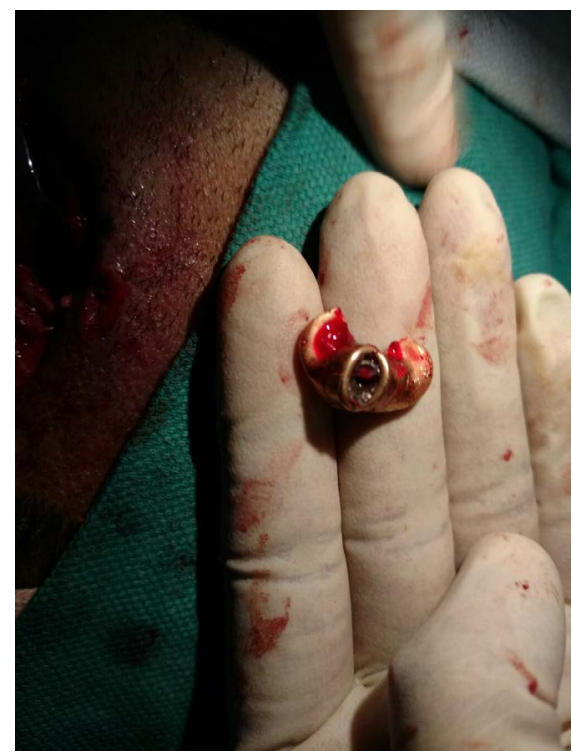

Figure 4. Showing the Bullet after removal.

successful outcome depends on careful planning and multidisciplinary team approach. In our case, we would also like to highlight that the use of endoscope was extremely helpful and helped us to avoid the morbidity associated with external approach.

\section{References}

1. Sansare K, Khnna V, Karjodkar F (2011) The role of maxillofacialradiologist in gunshot injuries-a hypothesizedmissile trajectory in two case reports. Dentomaxillofac Radiol 40: 53-59. [Crossref]
2. Kennedy F, Sullivan J, Arellano D, Roulier R (2000) Evaluating the role of physical and radiological examination in assessing bullet tract termination for gunshot victims. Am Surg. 66: 296-301.

3. Dourado E, Gomes AC (2008) Surgical removal of metallic foreign in face-Case report Odontologia Clin Cientif Recife 7: 161-164.

4. Saidi HS, Nyakiamo J, Faya S (2002) Gunshot injuries as seen at the Aga Khan Hospital, Nairobi, Kenya. East Afr Med J 79:188-192. [Crossref]

5. Dimitroulis G (2006) An unusual bullet trajectory to the face. J Oral Maxillofac Surg. 64: 137-139. [Crossref]

6. Hauer T, Huschitt N, Kulla M, Kneubuehl B, Willy C (2011) [Bullet and shrapnel injuries in the face and neck regions. Current aspects of wound ballistics]. HNO 59: 752-764. [Crossref]

7. Bartlett CS, Helfet DL, Hausman MR, Strauss E (2000) Ballistic and gunshot wounds: Effects on musculoskeletal tissues. J Am Acad Orthop Surg 8: 21-36. [Crossref]

8. Kikano GE, Stange KC (1992) Lead poisoning in a child after a gunshot injury. J Farm Pract 34: 498-500. [Crossref]

9. Greenberg SR (1990) The histopathology of tissue leads retention. Histol Histopathol 5: 541-546. [Crossref]

10. Jansen DL, Tirman PF, Rabassa AE, Kumar S (1995) Lead bursogram and focal synovitis secondary to a retained intrarticular bullet fragment. Skeletal Radiol 24: 142144. [Crossref]

11. Cavalieri Costa R, Stape CA, Suzuki I, Targa WH, Batista MA, et al. (1994) Lead poisoning caused by bullet in the hip. Report of 2 cases. Rev Hosp Clin Fac Med São Paulo 49: 124-127.

12. Lee D, Nash M, Turk J, Har-El G (1997) Low-velocity gunshot wounds to the paranasal sinuses. Otolaryngol Head Neck Surg 116: 372-378. [Crossref]

13. Mahajan M, Shah N (2004) Accidental lodgment of an air gun pellet in the maxillary sinus of a 6-year old girl: a case report. Dent Traumatol 20: 178-180. [Crossref]

14. Long V, Lo LJ, Chen YR (2002) Facial Reconstruction after a complicated gunshot injury. Chang Gung Med J 25: 557-562. [Crossref]

Copyright: $(02017$ Sathe NU. This is an open-access article distributed under the terms of the Creative Commons Attribution License, which permits unrestricted use, distribution, and reproduction in any medium, provided the original author and source are credited. 